\title{
The Biosynthesis of Carbamoyl Phosphate in Saccharomyces cerevisiae
}

\author{
By F. LACROU'TE \\ Laboratoire de Génétique Physiologique de C.N.R.S., Gif-sur-Yvette, \\ Seine et Oise, France \\ AND A. PIÉRARD, MARCELLE GRENSON AND J. M. WIAME \\ Laboratoire de Microbiologie, Université de Bruxelles and Institut de \\ Recherches du C.E.R.I.A., Bruxelles 7, Belgium
}

(Received 3 February 1965)

\begin{abstract}
SUMMARY
Mutants of Saccharomyces cerevisiae impaired in the biosynthesis of carbamoyl phosphate were obtained. Genetical, physiological and enzymic studies of these mutants showed the existence in this organism of two independent enzymic systems which catalysed the synthesis of carbamoyl phosphate from $\mathrm{HCO}_{3}{ }^{-}$, glutamine, ATP and $\mathrm{Mg}^{2+}$. One system provides carbamoyl phosphate for the arginine pathway, the other plays a similar role for the pyrimidine pathway. Carbamoyl phosphate from one pathway is freely available for the other. The mutations have been mapped in three unlinked loci. Two loci determine the argininespecific carbamoyl phosphate synthesizing system. The third locus corresponds to the pyrimidine-specific system. Mutations in either of the two genes concerned with the arginine pathway lead to a deficiency in the activity of that pathway to synthesize carbamoyl phosphate. Crossing a mutant deficient in one of the two arginine loci with a mutant deficient at the other produces a diploid in which complementation occurs. Also, in vitro activity may be partially regained by combining the cell-free extracts of the two single mutants. The physiological significance of the two enzymic systems is established by the study of their regulation. The carbamoyl phosphate synthesizing activity of the arginine pathway was repressed to $10 \%$ of its value in minimal medium by addition of excess of arginine to the growth medium. The activity corresponding to the pyrimidine pathway was only slightly repressed by uracil but was subject to feed-back inhibition by uridine-5'-triphosphate. These results are compared with the data available for other micro-organisms.
\end{abstract}

\section{INTRODUCTION}

Interest in the mechanism of the biosynthesis of carbamoyl phosphate is justified by its key role as a common precursor of two important biosynthetic pathways: that of arginine and that of the pyrimidines. For this reason, a complex regulation of the biosynthesis of carbamoyl phosphate may be expected. The nature of the reactions responsible for this biosynthesis is not well known in micro-organisms.

The reaction catalysed by carbamoyl phosphokinase (ATP: carbamate phosphotransferase; E.C. 2. 7. 2. 2),

$$
\mathrm{NH}_{2} \mathrm{COO}^{-}+\mathrm{ATP} \stackrel{\mathrm{Mg}^{2+}}{\rightleftharpoons} \mathrm{NH}_{2}-\mathrm{CO}_{2} \mathrm{PO}_{3}^{2-}+\mathrm{ADP} \text {, }
$$


was the first to be proposed as the route of formation of carbamoyl phosphate in micro-organisms (Jones, Spector \& Lipmann, 1955; Gorini \& Kalman, 1963; Davis, 1963). Others see in Levenberg's glutamine-dependent reaction (Levenberg, 1962):

$$
\text { glutamine }+\mathrm{ATP}+\mathrm{HCO}_{3} \stackrel{-}{-} \stackrel{\mathrm{Mg}^{2+}+}{\longrightarrow} \mathrm{NH}_{2}-\mathrm{CO}_{2} \mathrm{PO}_{3}{ }^{2-}+\mathrm{ADP}+\text { glutamate, }
$$

the functional mechanism of that biosynthesis (Piérard \& Wiame, 1964).

In Escherichia coli one-step mutants simultaneously auxotrophic for arginine and uracil have been obtained (Roepke, 1946; Davis, B. D., 1962). Other mutants, which require arginine when uracil is present in the growth medium, are known (Novick \& Maas, 1961; Gorini \& Kalman, 1963). All of these mutants are located within the same small genetic region (Piérard, Glansdorff \& Mergeay, in preparation; Beckwith, Pardee, Austrian \& Jacob, 1962). Thus, it would appear that a single enzymic system synthesizes carbamoyl phosphate for both pathways in this organism. A different situation exists in Neurospora. Indirect but extensive evidence from genetic studies led to the opinion that there were two independent enzymic syntheses of carbamoyl phosphate in Neurospora, one specific for the arginine, the other for the pyrimidine pathway (Davis, R. H., 1962; Reissig, 1960, 1963; Charles, 1962). Carbamoyl phosphate formed by one reaction is not freely available for the other pathway (Davis \& Woodward, 1962; Davis, 1963). This channelling leads the mutants to be auxotrophic either for arginine or for pyrimidine. Supporting this view Davis (1963) has identified the reaction specific for the arginine pathway as mediated by a carbamoyl phosphokinase which is repressible by arginine and which is not present in the arg-3 mutant. This enzyme affected by the mutation concerning the pyrimidine-specific pathway, has not yet been identified.

The data obtained in the present work show that in Saccharomyces cerevisiae the enzymic reaction leading to carbamoyl phosphate uses glutamine as the nitrogen donor (Levenberg, 1962). Direct enzymic evidence will be presented for the existence of two different enzymes. Mutations which affect each one separately have been found, thus allowing the study of them independently. One enzyme is related to the pyrimidine pathway, since it is strongly retro-inhibited by uridine$\mathbf{5}^{\prime}$-triphosphate (UTP); the other, while unaffected by UTP, is strongly repressed by arginine. Either enzymic system alone permits growth, showing that there is no channelling of carbamoyl phosphate in S. cerevisiae. As expected, strains unable to conduct both reactions required to be given arginine + uracil for growth. A preliminary report of this work has appeared (Lacroute, Piérard, Grenson \& Wiame, 1964).

\section{METHODS}

Organisms. The yeast strains used are haploid clones of Saccharomyces cerevisiae which are heterothallic. Mutants $c p u$ and $c p a_{2}$ were obtained by using nitrous acid as mutagen, mutants $c p a_{1-1}$ and $c p a_{1-2}$ by using X-rays. (Mutant cpa was named $\mathrm{E}_{1}{ }^{-}$and mutant $c p u, \mathrm{E}_{2}-$ in our preliminary note; Lacroute et al. 1964; Lacroute, 1964). Mutant $\mathrm{DE}_{14}\left(a r_{3}\right)$ was kindly provided by Dr R. K. Mortimer and identified by us as blocked in ornithine carbamoyltransferase (E.C. 2. 1. 3. 3).

Genetical methods. Diploids were obtained and isolated, and tetrad analysis was done as described by Hawthorne \& Mortimer (1960). 
Media used and conditions of growth. The basal medium for growth was a defined basal medium (no. 140) containing (per l. medium): $\mathrm{MgSO}_{4} .7 \mathrm{H}_{2} \mathrm{O}, 0.7 \mathrm{~g}$.; $\mathrm{KH}_{2} \mathrm{PO}_{4}, 1 \mathrm{~g}$.; $\mathrm{CaCl}_{2}, 0.4 \mathrm{~g}$; $\mathrm{NaCl}, 0.5 \mathrm{~g}$; $\left(\mathrm{NH}_{4}\right)_{2} \mathrm{SO}_{4}, 1.2 \mathrm{~g}$; citric acid, 10.5 g.; $10 \mathrm{M}-\mathrm{KOH}, 16 \mathrm{ml}$; trace metals solution, $1 \mathrm{ml}$. One 1 . of trace metals solution contained: $\mathrm{H}_{3} \mathrm{BO}_{3}, 500 \mathrm{mg}$; $\mathrm{CaSO}_{4} .5 \mathrm{H}_{2} \mathrm{O}, 40 \mathrm{mg}$.; $\mathrm{KI}, 100 \mathrm{mg}$; $\mathrm{FeCl}_{3} .6 \mathrm{H}_{2} \mathrm{O}, 5 \mathrm{~g}$.; $\mathrm{MnSO}_{4} 4 \mathrm{H}_{2} \mathrm{O}, 400 \mathrm{mg}$; $\mathrm{Na}_{2} \mathrm{MoO}_{4} \cdot 2 \mathrm{H}_{2} \mathrm{O}, 200 \mathrm{mg}$.; $\mathrm{ZnSO}_{4} \cdot 7 \mathrm{H}_{2} \mathrm{O}, 720 \mathrm{mg}$; citric acid, $10 \mathrm{~g}$.

The medium was adjusted to $\mathrm{pH} 6 \cdot 15$ before sterilization. After autoclaving $\left(121^{\circ}, 20 \mathrm{~min}\right.$.), glucose (to final concentration $3 \mathrm{~g} . / 100 \mathrm{ml}$.) and a solution of vitamins (final dilution $1 / 100$ ) were added to the medium. The vitamin solution was composed as follows (per 1.): DL-calcium panthotenate, $200 \mathrm{mg}$; biotin, $250 \mu \mathrm{g}$.; nicotinic acid, $100 \mathrm{mg}$.; thiamine, $100 \mathrm{mg}$.; riboflavin, $100 \mathrm{mg}$.; inositol, $500 \mu \mathrm{g}$.; $p$-aminobenzoic acid, $50 \mathrm{mg}$; pyridoxine, $100 \mathrm{mg}$.; folic acid (sterilized separately by filtration), $400 \mu \mathrm{g}$.

The cultures were grown aerobically on a rotary shaker at $30^{\circ}$.

Growth curves. Each organism was grown on the four following media: minimal medium (M); minimal medium + uracil (100 $\mu \mathrm{g} . / \mathrm{ml}$.); minimal + L-arginine $100 \mu \mathrm{g} . /$ ml.; minimal+uracil+arginine. The growth was followed by measuring the extinction in a Beckman model $\mathrm{C}$ colorimeter with an interference filter $(765 \mathrm{~m} \mu)$. Two different extinction values were used at inoculation: 0.100 and 0.001 (calculated) to obtain a sufficient number of generations in the exponential phase of growth.

Preparation of organisms for enzyme assays. Minimal medium was supplemented when started with $200 \mu \mathrm{g}$. L-arginine, uracil or both together $/ \mathrm{ml}$. Organisms were harvested during the exponential phase (extinction $0 \cdot 8-1 \cdot 6$, with a Hilger-Spekker colorimeter, equivalent to $0 \cdot 4-0.8 \mathrm{mg}$. dry wt. organism $/ \mathrm{ml}$.).

Double mutants FL 80-2C $\left(c p a_{2}, c p u\right)$ and $\Sigma 1320 c\left(c p a_{1}, c p u\right)$ were grown on limiting concentrations of arginine $(15 \mu \mathrm{g} . / \mathrm{ml}$.) and uracil $(7 \mu \mathrm{g} . / \mathrm{ml}$.). The organisms were collected one doubling-time after the end of the exponential phase of growth, to allow for de-repression. The organisms were collected by centrifugation, washed with distilled water and kept frozen until the preparation of cell-free extracts.

Cell-free extracts. Organisms harvested from $1.5 \mathrm{l}$. culture, were resuspended in $8 \mathrm{ml}$. $0.05 \mathrm{M}$ phosphate buffer $(\mathrm{pH} 7 \cdot 5)$ and broken in a Nossal cell disintegrator (MacDonald Engineering Co., 1725 Fall Avenue, Cleveland 13, Ohio, U.S.A.) with 8 g. glass beads; the breakage period was for 30 sec. twice with cooling with a stream of $\mathrm{CO}_{2}$ (Somlo, 1962). After centrifugation at 20,000 $\mathrm{g}$ for $30 \mathrm{~min}$. in a Servall SS-1 centrifuge, the supernatant fluid obtained (referred to as the crude extract), was passed once and in some experiments twice through a column of Sephadex G 25 (pre-treated with 0.05 M-phosphate, pH 7.5). Enzymic activities were determined shortly after the preparation of the cell-free extracts to avoid loss of the rather unstable carbamoyl phosphate synthesizing activity.

Assay of enzymes. The activities of carbamoyl phosphokinase and of glutaminedependent carbamoyl phosphate synthetase were determined by converting carbamoyl phosphate formed from radioactively labelled bicarbonate to acid-stable citrulline according to a modification of the method developed by Levenberg (1962) for the mushroom system.

The assay system for carbamoyl phosphokinase activity contained (in total 
volume $1 \mathrm{ml}$.): ATP, $20 \mu$ mole; $\mathrm{MgCl}_{2}, 25 \mu$ mole; ornithine, $10 \mu$ mole; tris buffer (pH 8.5), $200 \mu$ mole; $\mathrm{NH}_{4} \mathrm{Cl}, 50 \mu$ mole; ${ }^{14} \mathrm{C}-\mathrm{Na}_{2} \mathrm{CO}_{4}$ (specific activity from 2 to $4 \times 10^{4}$ c.p.m. $\left./ \mu \mathrm{mole}\right), 50 \mu$ mole; excess of ornithine carbamoyltransferase partially purified from Escherichia coli; crude extract. The reaction was started shortly after the addition of ${ }^{14} \mathrm{C}-\mathrm{Na}_{2} \mathrm{CO}_{4}$ by introducing the extract. Incubation was for $30 \mathrm{~min}$. at $30^{\circ}$. The reaction was stopped by adding $1 \mathrm{ml}$. of $2 \mathrm{~N}-\mathrm{HCl}$, followed by boiling for $10 \mathrm{~min}$. After removal by centrifugation of the precipitated proteins, samples of the reaction mixture were plated on copper planchets. The samples were evaporated to dryness and the radioactivity in the acid-stable samples counted in a (Nuclear Chicago) low background gas-flow counter.
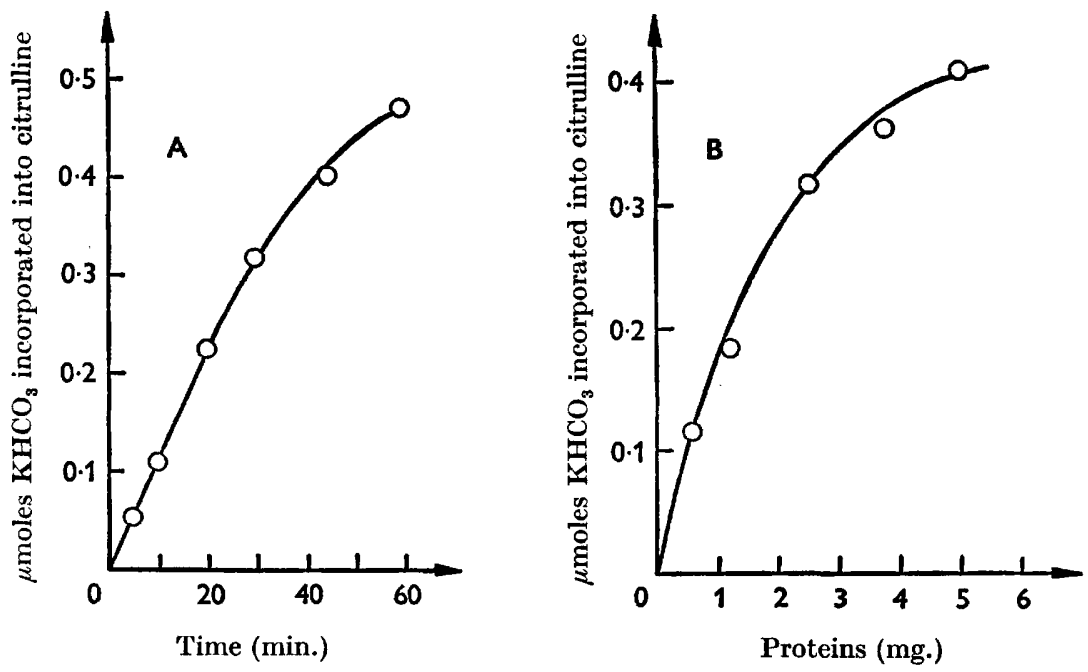

Fig. 1. Glutamine-dependent carbamoyl phosphate synthetase activity. Dependence of incorporation of $\mathrm{KHCO}_{3}$ in citrulline on time (A) and amount of Sephadex-treated extract (B) of Saccharomyces cerevisiae mutant FL 82-25C (cpu). In A, the amount of protein is $2.52 \mathrm{mg}$. In $B$, incubation time $30 \mathrm{~min}$.

The constituents of the reaction mixture for the assay of the glutamine-dependent carbamoyl phosphate synthetase were as follows: in $1 \mathrm{ml}$. total volume: phosphate buffer ( $\mathrm{pH} 7 \cdot 5$ ), $85 \mu$ mole; ATP, $12 \mu$ mole; $\mathrm{MgCl}_{2}, 12 \mu$ mole; ornithine, $6 \mu$ mole; glutamine, $6 \mu$ mole; ${ }^{14} \mathrm{C}-\mathrm{KHCO}_{3}$ (specific activity from 4 to $8 \times 10^{4}$ c.p.m./ $\mu$ mole), $30 \mu$ mole; excess of ornithine carbamoyltransferase partially purified from Escherichia coli; cell-free extract. Incubation and counting procedures were as described for the carbamoyl phosphokinase activity. Under these conditions, a reasonable linearity of citrulline production with time and amount of extract was obtained (Fig. 1). All the values given have been corrected for controls where the reaction was stopped at zero time. Under the conditions used, no corrections for self-absorption were necessary. Specific activities are expressed as $\mathrm{m} \mu \mathrm{moles}$ radioactive bicarbonate incorporated into citrulline $/ \mathrm{hr} / \mathrm{mg}$. protein.

Identification of ${ }^{14} \mathrm{C}$-labelled products. The identity of the ${ }^{14} \mathrm{C}$-labelled products obtained by coupling carbamoyl phosphate synthesis with ornithine carbamoyltransferase or with aspartate carbamoyltransferase, was confirmed by the use of high voltage $(5 \mathrm{kV}$.) electrophoresis in acetate buffer $(\mathrm{pH} 3)$ and by paper chromato- 
graphy with 2 -butanol $+88 \%$ formic acid in water + water $(75+15+10$, by vol.) as solvent (Bishop \& Campbell, 1963). The paper strips were passed through a Nuclear Chicago chromatogram scanner. Comparison with samples of authentic ${ }^{14} \mathrm{C}$-ureido compounds confirmed that the radioactivity from ${ }^{14} \mathrm{C}$-bicarbonate was incorporated into citrulline or ureidosuccinic acid. A third radioactive peak corresponded to a non-identical degradation product of these compounds; this through a non-enzymic reaction favoured by ATP. Nevertheless, the results were not quantitatively affected because this degradation product was acid-stable.

\section{RESULTS}

Genetic analysis and physiological properties of the mutants

To study the biosynthesis of carbamoyl phosphate Saccharomyces cerevisiae, we tried to isolate mutants which required simultaneously uracil and arginine for growth. We obtained such a strain (FL 80-2C) but genetic analysis showed that it had undergone two mutations. The physiological consequences of these mutations and the phenotypes of all the mutants obtained from it are described in Table 1. The independence of the two mutations is shown in Table 2 (cross no. 1). One of these

\section{Table 1. Growth behaviour of various mutants of Saccharomyces cerevisiae deficient in the biosynthesis of carbamoyl phosphate}

\begin{tabular}{|c|c|c|c|c|c|}
\hline & & \multicolumn{4}{|c|}{ Culture medium } \\
\hline \multicolumn{2}{|c|}{ S. cerevisiae } & Minimal & $\begin{array}{c}\text { Minimal } \\
+ \text { arginine }\end{array}$ & $\begin{array}{r}\text { Minimal } \\
+ \text { uracil }\end{array}$ & $\begin{array}{l}\text { Minimal } \\
\text { + arginine } \\
\text { + uracil }\end{array}$ \\
\hline & & & & & \\
\hline & & & & & \\
\hline FL 100 & Wild & + & + & + & + \\
\hline$\Sigma 1330 a$ & $c p a_{1}$ & + & + & - & + \\
\hline FL 80-2A & $c p a_{2}$ & + & + & - & + \\
\hline FL 82-25C & $c p u$ & + & \pm & + & + \\
\hline$\Sigma 1320 \mathrm{c}$ & $c p a_{1}, c p u$ & - & - & - & + \\
\hline FL 80-2C & $c p a_{2}, c p u$ & - & - & - & + \\
\hline$\Sigma 1461 b$ & $c p a_{1}, c p a$ & + & + & - & + \\
\hline
\end{tabular}

mutations (mutant $c p a_{2}$ ) led in the presence of uracil to a requirement for arginine, while the phenotype was of wild-type in the absence of added uracil. The growth rate of $S$. cerevisiae strains which carried the second mutation (cpu) was slightly lower in the presence of arginine and this partial inhibition was annulled by uracil. Once isolated each of the mutations showed a regular 2:2 segregation when crossed with a wild-type strain. When both mutations were present in the same strain, an $u r^{-} a r^{-}$phenotype was obtained. These properties are seen in Fig. 2, which shows the growth curve of the four types of strains. Figure $2 \mathrm{D}$ shows the rapid inhibition of growth of a mutant $c p a_{2}$ after adding uracil to a minimal medium (upper curve). In the same experiment, starting from a lower extinction value $(0 \cdot 001$, calculated) no detectable growth occurred in minimal medium + uracil. Figure $2 \mathrm{C}$ shows that, in contrast with the preceding case, the effect of arginine on a cpu mutant was much more delayed and less important.

Two other mutants with the same phenotype as mutant $c p a_{2}$ (requirement for 


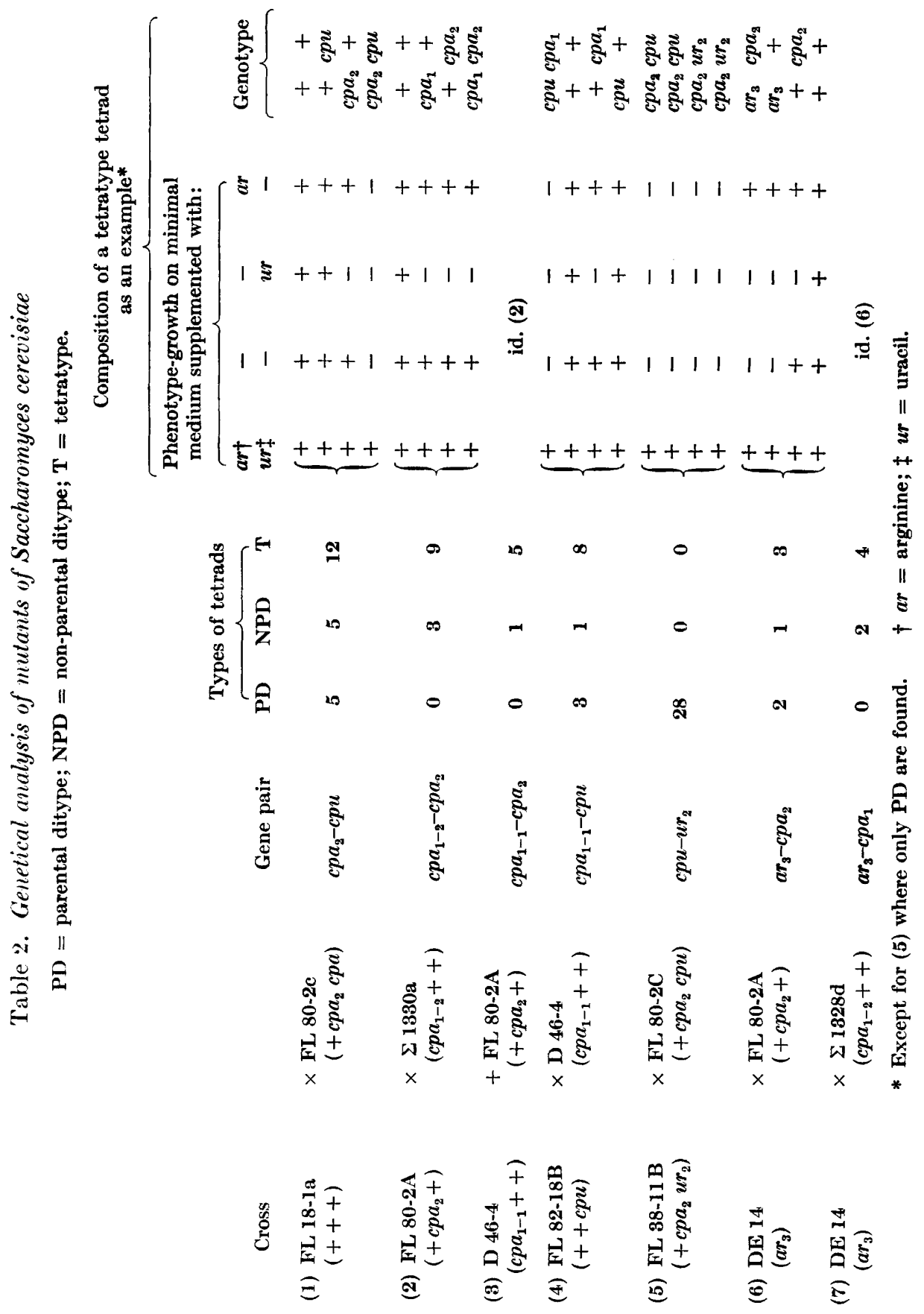


arginine in presence of uracil) were isolated independently. Each of them contained a single mutation showing the normal 2:2 segregation. The two mutations were allelic, as shown by the absence of complementation and by the mutant phenotype of the haploid descendants from a cross between them; we call these mutants $c p a_{1-1}$ and $c p a_{1-2}$. A strain of Saccharomyces cerevisiae with a similar inhibition of growth by uracil, which was annulled specifically by arginine was described by Miller \& Harrison (1950).
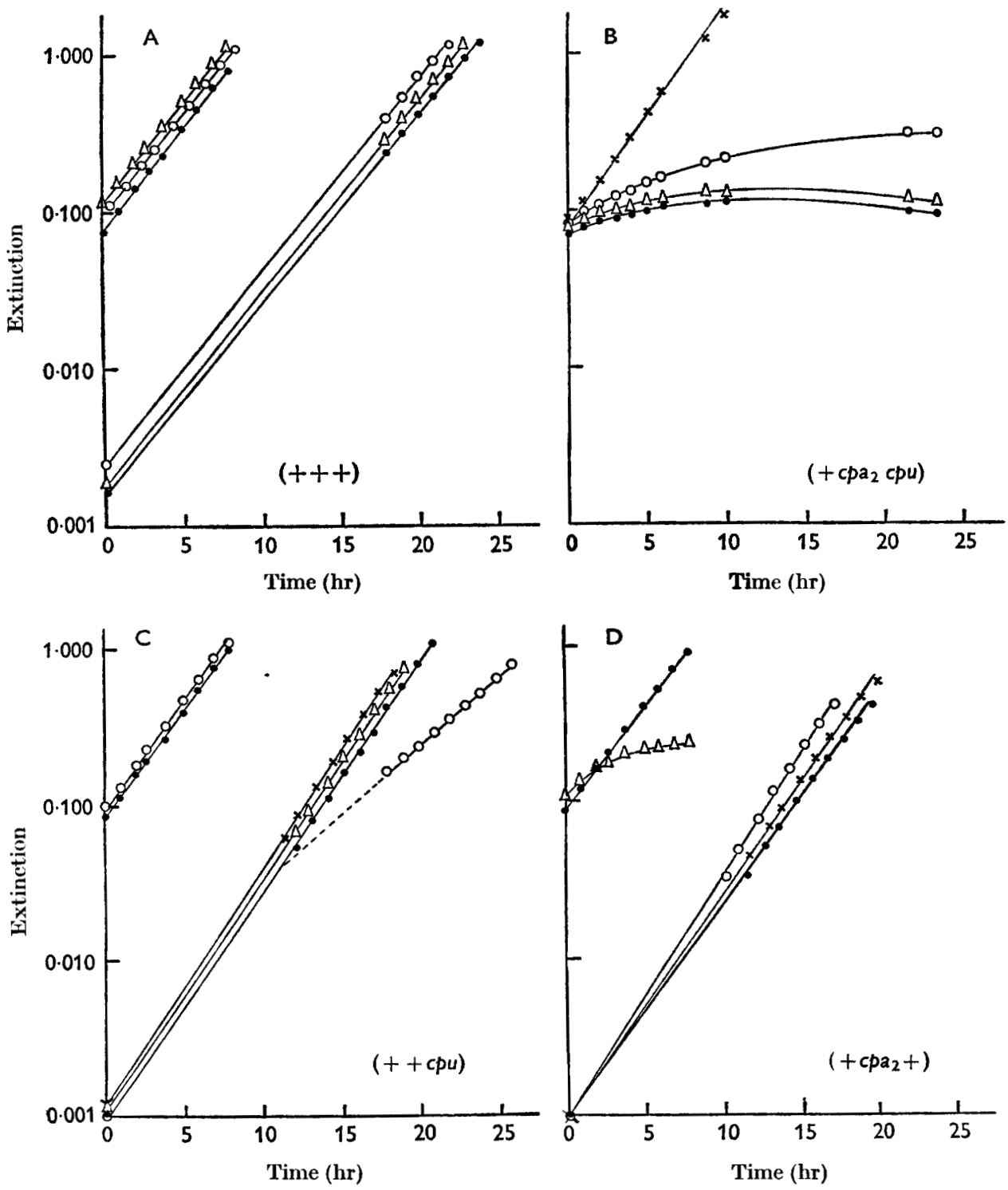

Fig. 2. Growth behaviour of the mutants. Two sets of curves are given for each strain, one starting from extinction $0 \cdot 100$ and one from extinction $0 \cdot 001$ (calculated). $\odot$, Minimal medium (M); $\triangle, M+$ uracil $(100 \mu \mathrm{g} . / \mathrm{ml}.) ; O, M+L-a r g i n i n e ~(100 \mu \mathrm{g} . / \mathrm{ml}.) ; \times, M+$ L-arginine + uracil. 
Strains of Saccharomyces cerevisiae carrying the mutation $c p a_{1-1}$ and $c p a_{1-2}$ were crossed with $c p a_{2}$ mutants to determine whether or not these mutations affected the same locus. Complementation tests and tetrad analysis showed that mutants $c p a_{1}$ and $c p a_{2}$ affected two different genes which segregated independently (Table 2, nos. 2 and 3). The simultaneous presence of $c p a_{1-1}$ or $c p a_{1-2}$ and $c p u$ in a strain gave the phenotype $u r^{-} a r^{-}$, as in the cases of mutants $c p a_{2}$ and $c p u$ (Table 2, no. 4). Finally, $c p u$ was shown to be allelic or very closely linked to $u_{2}$ (Table 2, no. 5), the structural gene of aspartate carbamoyltransferase (E.C. 2. 13. 2; Lacroute, 1964), whereas neither $c p a_{1}$ nor $c p a_{2}$ were genetically linked to $a r_{3}$, the structural gene of ornithine carbamoyltransferase (Table 2, nos. 6, 7).

Based on the genetic analysis and the physiological properties of the mutants obtained, we formulate the hypothesis that two independent carbamoyl phosphate synthesizing systems exist in Saccharomyces cerevisiae, one specific for the arginine pathway, the other for the pyrimidine pathway, genes $c p a_{1}$ and $c p a_{2}$ corresponding to the arginine system and gene $c p u$ to the pyrimidine system. In the following sections, we give further evidence in support of this hypothesis.

\section{Nature of the reaction responsible for the biosynthesis of carbamoyl phosphate}

In the study of the mechanism of the biosynthesis of carbamoyl phosphate in Saccharomyces cerevisiae we considered two possible reactions, one catalyzed by carbamoyl phosphokinase, the other by the glutamine-dependent carbamoyl phosphate synthetase. These carbamoyl phosphate synthesizing activities were

Table 3. Specific activities of carbamoyl phosphokinase and of glutamine-dependent carbamoyl phosphate synthetase of various mutants of Saccharomyces cerevisiae

Conditions are as described in 'Methods'. For carbamoyl phosphokinase activity $\mathrm{NH}_{4}{ }^{+}$was at $5 \times 10^{-2} \mathrm{M}$, glutamine at $6 \times 10^{-3} \mathrm{M}$. For the glutamine-dependent carbamoyl phosphate synthetase, both $\mathrm{NH}_{4}{ }^{+}$and glutamine were at $6 \times 10^{-3} \mathrm{M}$.

\begin{tabular}{|c|c|c|c|c|c|}
\hline \multirow[b]{2}{*}{ Mutant } & \multirow[b]{2}{*}{$\begin{array}{c}\text { Amino group } \\
\text { donor }\end{array}$} & \multicolumn{2}{|c|}{$\begin{array}{c}\text { Carbamoyl } \\
\text { phosphokinase } \\
\text { activity }\end{array}$} & \multicolumn{2}{|c|}{$\begin{array}{l}\text { Glutamine-dependent } \\
\text { carbamoyl phosphate } \\
\text { synthetase activity }\end{array}$} \\
\hline & & $\begin{array}{l}\text { Crude } \\
\text { extract }\end{array}$ & $\begin{array}{c}\text { Sephadex- } \\
\text { treated } \\
\text { extract }\end{array}$ & $\begin{array}{l}\text { Crude } \\
\text { extract }\end{array}$ & $\begin{array}{l}\text { Sephadex- } \\
\text { treated } \\
\text { extract }\end{array}$ \\
\hline $\begin{array}{l}\text { FL } 100 \\
\text { (wild) }\end{array}$ & $\begin{array}{l}\text { None } \\
\mathrm{NH}_{4}{ }^{+} \\
\text {Glutamine }\end{array}$ & $\begin{array}{l}19 \\
40 \\
32\end{array}$ & $\begin{array}{r}1 \\
12 \\
33\end{array}$ & $\begin{array}{r}99 \\
78 \\
100\end{array}$ & $\begin{array}{r}2 \\
5 \\
78\end{array}$ \\
\hline $\begin{array}{l}\text { FI, 80-2A } \\
\left(c p a_{2}\right)\end{array}$ & $\begin{array}{l}\text { None } \\
\mathrm{NH}_{4}{ }^{+} \\
\text {Glutamine }\end{array}$ & $\begin{array}{l}3 \\
4 \\
3\end{array}$ & $\begin{array}{l}\mathbf{1} \\
\mathbf{0} \\
\mathbf{1}\end{array}$ & $\begin{array}{l}29 \\
26 \\
36\end{array}$ & $\begin{array}{r}1 \\
1 \\
15\end{array}$ \\
\hline $\begin{array}{l}\text { FL 82-25C } \\
(c p u)\end{array}$ & $\begin{array}{l}\text { None } \\
\mathrm{NH}_{4}{ }^{+} \\
\text {Glutamine }\end{array}$ & $\begin{array}{l}17 \\
49 \\
46\end{array}$ & $\begin{array}{r}1 \\
13 \\
55\end{array}$ & $\begin{array}{l}27 \\
58 \\
85\end{array}$ & $\begin{array}{r}2 \\
5 \\
100\end{array}$ \\
\hline $\begin{array}{l}\text { FL } 80-2 \mathrm{C} \\
\left(c p a_{2}, c p u\right)\end{array}$ & $\begin{array}{l}\text { None } \\
\mathrm{NH}_{4}^{+} \\
\text {Glutamine }\end{array}$ & $\begin{array}{l}3 \\
4 \\
3\end{array}$ & $\begin{array}{l}2 \\
2 \\
2\end{array}$ & $\begin{array}{l}9 \\
8 \\
9\end{array}$ & $\begin{array}{l}\mathbf{3} \\
\mathbf{4} \\
\mathbf{3}\end{array}$ \\
\hline $\begin{array}{l}\sum 1320 \mathrm{C} \\
\left(c p a_{1}, c p u\right)\end{array}$ & $\begin{array}{l}\text { None } \\
\mathrm{NH}_{4}{ }^{+} \\
\text {Glutamine }\end{array}$ & - & $\begin{array}{l}0 \\
0 \\
0\end{array}$ & - & $\begin{array}{l}\mathbf{3} \\
\mathbf{3} \\
\mathbf{3}\end{array}$ \\
\hline
\end{tabular}


determined for the various mutants described in the preceding section. For each strain, the activities for the crude and for the Sephadex-treated extracts were estimated; the results are shown in Table 3.

Crude extracts of the wild-type strain (FL 100) of Saccharomyces cerevisiae exhibited considerable activity for both reactions. However, these activities were little dependent on the presence of added ammonium ion or glutamine. After Sephadex treatment, the carbamoyl phosphokinase activity was only partially

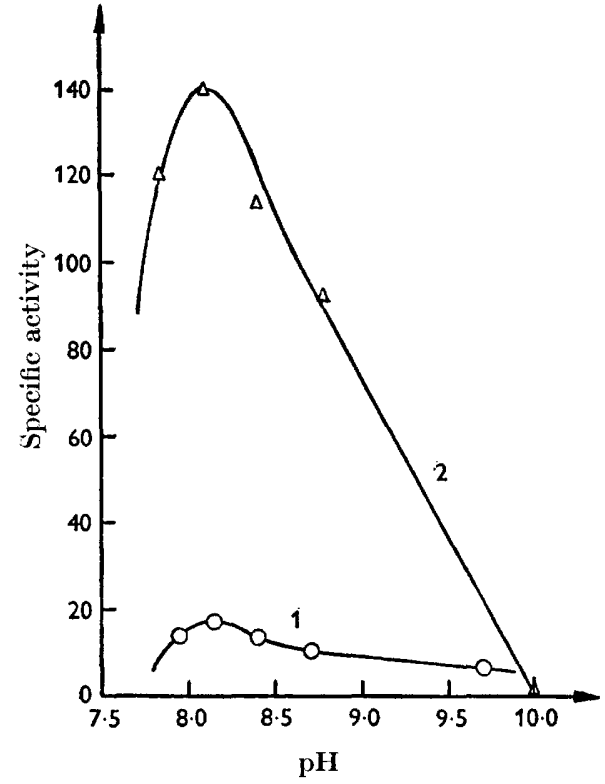

Fig. 3

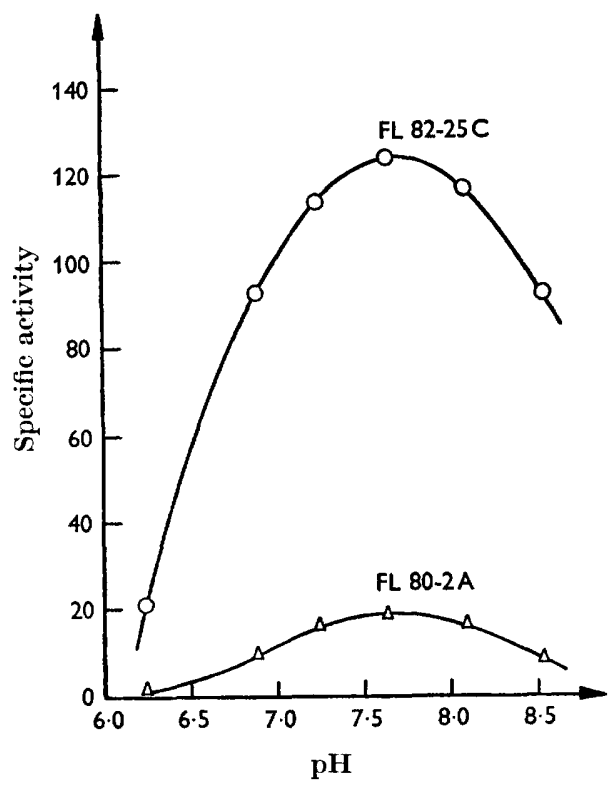

Fig. 4

Fig. 3. Variation with $\mathrm{pH}$ value of activities of carbamoyl phosphate synthesis with $\mathrm{NH}_{4}^{+}$or glutamine. Conditions described in Methods for estimation of carbamoyl phosphokinase activity (curve 1 ). In curve $2, \mathrm{NH}_{4}+$ replaced by $6 \times 10^{-3} \mathrm{M}$-glutamine. The extract was treated twice with Sephadex $\mathrm{G} \mathrm{25,} \mathrm{pH}$ value measured at the beginning of incubation.

Fig. 4. Variations with $\mathrm{pH}$ value of the activity of glutamine-dependent carbamoyl phosphate synthesis of $S$. cerevisiae mutants FL 82-25C (cpu) and FL 80-2A $\left(c p a_{2}\right)$. Conditions as described in Methods. Extract treated with Sephadex G 25; pH value measured at the beginning of incubation.

recovered in presence of $\mathrm{NH}_{4}{ }^{+}\left(5 \times 10^{-2} \mathrm{M}\right)$, but was fully restored when $\mathrm{NH}_{4}{ }^{+}$was replaced by $6 \times 10^{-3} \mathrm{M}$-glutamine. Under the assay conditions of the glutaminedependent carbamoyl phosphate synthetase activity, glutamine $\left(6 \times 10^{-3} \mathrm{M}\right)$ was not efficiently replaced by an equivalent concentration of ammonium ion. A similar situation was observed with mutants FL 80-2 A $\left(c p a_{2}\right)$ and FL 82-25C (cpu). An important difference in the amount of carbamoyl phosphate synthetase of these two mutants should be noted (Table 3). Finally, the double mutants, FL 80-2 C $\left(c p a_{2}, c p u\right)$ and $\Sigma 1320 c\left(c p a_{1}, c p u\right)$ were almost totally deficient in both activities (Table 3).

Most of the carbamoyl phosphokinase activity seems due to the presence of glutamine in the crude extract which is eliminated by the Sephadex treatment. 
Nevertheless, the Sephadex-treated extract showed a weak activity with $\mathrm{NH}_{4}^{+}$, activity better explained by assuming a small affinity of the synthetase for this ion. This is well illustrated in Fig. 3, where the variations of the activities with pH value were recorded with glutamine or $\mathrm{NH}_{4}^{+}$as the nitrogen donor. The activity with $\mathrm{NH}_{4}{ }^{+}$varied in parallel with the activity with glutamine. On the basis of the data presented here, it seems reasonable to conclude that in $S$. cerevisiae, the activity ascribed to carbamoyl phosphokinase corresponds to a weak activity with $\mathrm{NH}_{4}{ }^{+}$of glutamine-dependent carbamoyl phosphate synthetase.

Table 4. Requirements for substrates and co-factors of the reactions catalysed by glutamine-dependent carbamoyl phosphate synthesizing activity of Saccharomyces cerevisiae mutants $F L ~ 80-2 A$ and $F L$ 82-25 C.

The experimental procedure is described under Methods. Extracts treated twice on Sephadex G 25 column were used.

\begin{tabular}{|c|c|c|}
\hline & $\begin{array}{c}\text { Mutant } \\
\text { FL 82-25C } \\
(c p u)\end{array}$ & $\begin{array}{l}\text { Mutant } \\
\text { FL 80-2A } \\
\quad\left(c p a_{2}\right)\end{array}$ \\
\hline & \multicolumn{2}{|c|}{ Specific activities } \\
\hline & & \\
\hline $\begin{array}{l}\text { Complete } \\
\text { without glutamine }\end{array}$ & $\begin{array}{r}134 \\
2\end{array}$ & $\begin{array}{r}11 \\
2\end{array}$ \\
\hline without ATP & o & o \\
\hline without $\mathrm{Mg}^{2+}$ & $\mathbf{1}$ & $\mathbf{0}$ \\
\hline without ornithine & 10 & $\mathbf{5}$ \\
\hline
\end{tabular}

Properties of the glutamine-dependent carbamoyl phosphate synthetase activities

To study independently the carbamoyl phosphate synthesizing activities related to the arginine and the pyrimidine pathways, we used mutants FL 82-25C (cpu) and FL 80-2 $\mathrm{A}\left(\mathrm{cpa}_{2}\right)$. The substrates and cofactors requirements of both activities were determined (Table 4). Incorporation of radioactivity from ${ }^{14} \mathrm{C}$-bicarbonate into citrulline by a cell-free extract of mutant FL 82-25C (cpu) was dependent on glutamine, ATP, $\mathrm{Mg}^{2+}$ and ornithine; ornithine was required for the conversion of carbamoyl phosphate to citrulline through ornithine carbamoyltransferase. The activity of mutant FL 80-2A $\left(c p a_{2}\right)$, although weaker than that of FL 82-25C (cpu), exhibited the same requirements. Acetylglutamate, an activator of the mammalian carbamoyl phosphate synthetase (Cohen, 1962) did not enhance the activity of the yeast carbamoyl phosphate synthetases. The weak activity of mutant FL 80-2A led us to consider that this activity might differ in some way from that of mutant FL 82-25 C. We therefore tested asparagine as an amino group donor in the reaction. However, asparagine behaved as a poor amino donor for carbamoyl phosphate synthesis with both mutants. As shown in Fig. 4, the activities of mutants FL 82-25C (cpu) and FL 80-2 A were not differentiated by their pH optima. The acid-stable product of both activities was citrulline in presence of ornithine, and ornithine carbamoyltransferase or ureidosuccinate in the presence of aspartate and aspartate carbamoyltransferase. The identification of these products is described above. 
Regulation of the two carbamoyl phosphate synthetases

To obtain evidence of the physiological meaning of the two glutamine-dependent carbamoyl phosphate synthetases, we studied the effect of arginine and uracil in the growth medium on these activities; the results are given in Table 5 . The activity of the single mutant FL 82-25 C ( $c p u$ ), which retained only the carbamoyl phosphate synthetase related to the arginine pathway, was strongly repressed by arginine in

Table 5. Influence of the addition of arginine and uracil to the growth medium on the degree of glutamine-dependent carbamoyl phosphate biosynthesis by mutants of Saccharomyces cerevisiae

Arginine and uracil in the growth medium were at $200 \mu \mathrm{g} . / \mathrm{l}$.

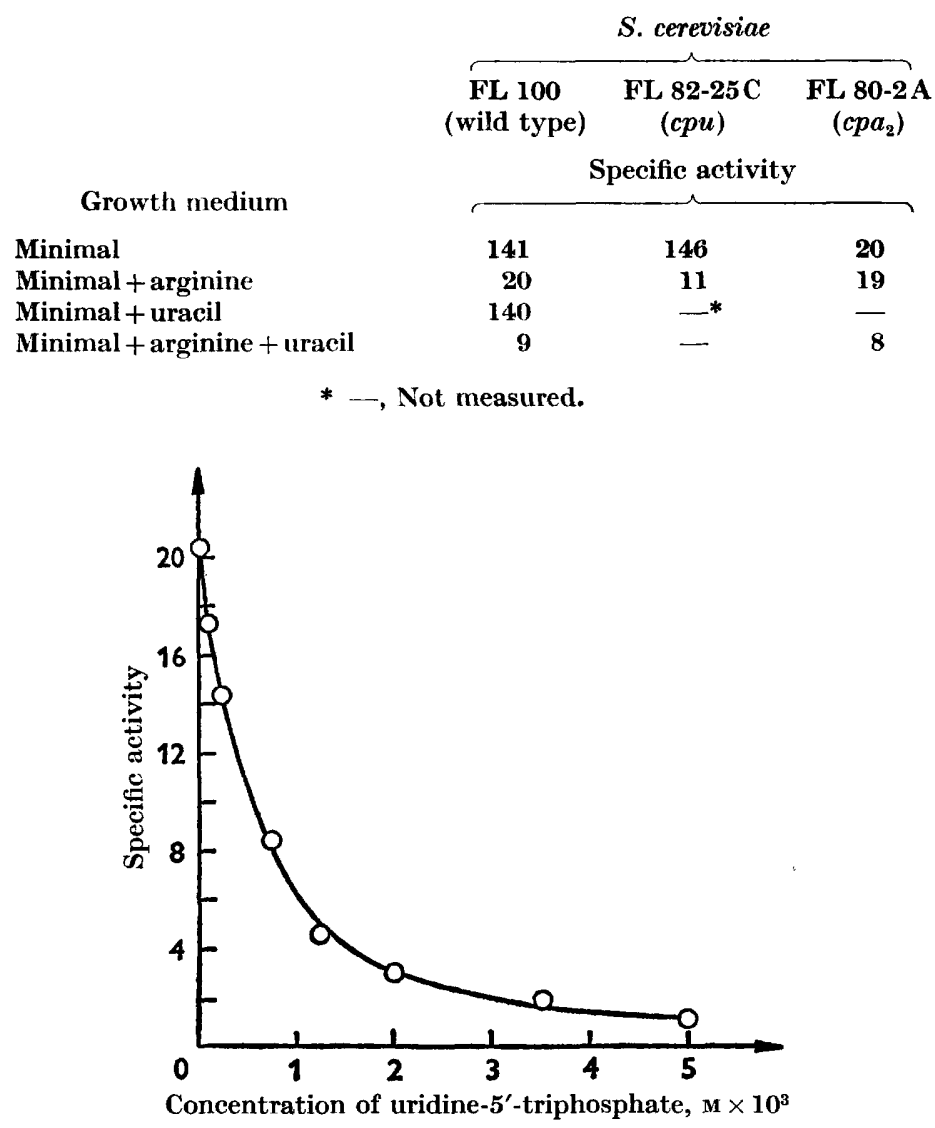

Fig. 5. Inhibition of UTP of the glutamine-dependent carbamoyl phosphate synthetase of mutant FL 80-2A $\left(\mathrm{cpa}_{2}\right)$. Experimental procedure as described in Methods; the extract used was treated twice with Sephadex G 25.

the growth medium. On genetic grounds, we supposed that the mutant FL 80-2 A (cpa) possessed only the activity specific for the pyrimidine pathway. Indeed, no repression of this activity by arginine was noted, but a limited repression by uracil was observed (Table 5). The activities of the wild-type strain can be explained by 
combination of the values given for the single mutants (within experimental error).

The repression by arginine of the carbamoyl phosphate synthetase specific for its own pathway allows an explanation of the behaviour of the single mutant FL 82-25 C $(c p u)$ : due to repression by arginine, the activity of carbamoyl phosphate synthesis becomes too low to support a normal growth rate. The action of arginine appears only several generations after the addition of arginine to the medium, in other words, when the repressed value has been reached. This delayed action of arginine is consistent with the large difference in activity between the carbamoyl phosphate synthesizing systems specific to the two pathways.

An additional feature of the regulation of these activities was obtained from the observation of a feed-back inhibition by uridine- $5^{\prime}$-triphosphate (UTP), and to a lesser degree by uridine-5'-monophosphate (UMP), of the carbamoyl phosphate biosynthesis linked to the pyrimidine pathway. UTP completely inhibited the activity at $5 \times 10^{-3} \mathrm{M}$ (Fig. 5); arginine or citrulline did not exert a similar action on the activity of the arginine pathway. This latter activity was not affected by UTP. The feed-back inhibition by UTP explains the inhibition by uracil of the growth of mutants blocked in the arginine-specific carbamoyl phosphate synthesizing system. When uracil was present in the medium, such mutants were unable to satisfy their requirements for carbamoyl phosphate needed for biosynthesis of arginine.

Table 6. In vivo and in vitro complementation of Saccharomyces cerevisiae mutants cpa $a_{1}$ and cpa $_{2}$ observed in cell-free extracts

Experimental procedure as described under 'Methods'. The cell-free extracts were treated twice on Sephadex G 25.

$\begin{array}{cc}\text { S. cerevisiae mutant strain } & \begin{array}{c}\text { Specific activity of } \\ \text { glutamine-dependent } \\ \text { carbamoyl phosphate } \\ \text { synthetase }\end{array} \\ \text { FL 80-2C }\left(c p a_{2}, c p u\right) & 2 \\ \Sigma 1320 c\left(c p a_{1}, c p u\right) & 1 \\ \text { FL 80-2C } \Sigma\left(320 c^{*}\right. & 17 \\ \text { Diploid mutant FL 80-2C } \times \Sigma 1320 c & 28 \\ \left(c p a_{2} c p u \times c p a_{1} c p u\right) & \\ \text { * The two extracts were mixed just before starting the incubation. }\end{array}$

Complementation between mutants cpa $a_{1}$ and $c p a_{2}$

We observed that the two non-allelic mutations $c p a_{1}$ and $c p a_{2}$ both lead to a block in the arginine-specific carbamoyl phosphate synthesizing system. However, these mutants were able to complement in the diploid strain which resulted from their cross. Cell-free extracts of the diploid strain obtained by crossing double mutants $\left(c p a_{1}, c p u\right)$ and $\left(c p a_{2}, c p u\right)$ showed an appreciable carbamoyl phosphate synthetase activity (Table 6 ). A significant activity was recovered by mixing the cell-free extracts of the same double mutants, which by themselves were devoided of such an activity (Table 6). 


\section{DISCUSSION}

Interest has been devoted recently to the study of the synthesis of carbamoyl phosphate in micro-organisms. These studies have been focused on the nature of the enzymic reaction and on the problems raised by the double function of carbamoyl phosphate biosynthesis.

The nature of the enzymic reaction responsible for the biosynthesis of carbamoyl phosphate is interesting to consider as against the reaction responsible for its breakdown. The latter function occurs in some species of Lactobacteriaceae and Pseudomonas. Carbamoyl phosphokinase, present in Lactobacteriaceae is inducible by arginine; the equilibrium is thermodynamically in favour of the breakdown of carbamoyl phosphate (Jones et al. 1955). The enzyme is responsible for the degradation of this compound (Jones, 1963; Thorne \& Jones, 1963). This enzyme catalyses the synthesis of carbamoyl phosphate in vitro, but its physiological meaning for biosynthesis is questionable. The recent finding by Grisolia et al. that acetylphosphokinase (ATP : acetate phosphotransferase; E.C. 2.7.2.1) can catalyse a reaction of the carbamoyl phosphokinase type, stresses the difficulty which may arise in identifying in vitro results with in vivo mechanisms (Grisolia \& Harmon, 1962; Grisolia, Amelunxen \& Raijman, 1963). The identification of an enzymic reaction with a physiological function is best established by the cumulative evidence from enzymic, genetical and regulation studies. In this connexion, the enzymic system which utilizes glutamine as nitrogen donor for the synthesis of carbamoyl phosphate in Escherichia coli, similar to the Agaricus system (Levenberg, 1962), satisfies all the above criteria (Piérard \& Wiame, 1964). Acetylphosphokinase has not been detected in yeast (Ochoa \& Stern, 1952). This permits the study of carbamoyl phosphate synthesis in Saccharomyces, without the interferences arising from the presence of that enzyme. The present work has shown that, after removal of the metabolites of the intracellular pool, the synthesis of carbamoyl phosphate is much greater with glutamine than with $\mathrm{NH}_{4}{ }^{+}$as nitrogen donor. This is true even under the optimal conditions for the assay of carbamoyl phosphokinase. If $\mathrm{NH}_{4}^{+}$ can serve as a nitrogen donor in the reaction, the speed and probably the affinity are probably much weaker than with glutamine.

In Neurospora the only donor of nitrogen for carbamoyl phosphate synthesis seems to be $\mathrm{NH}_{4}{ }^{+}$(Dr. R. H. Davis, personal communication). In Escherichia coli, the work of Yashphe \& Gorini, 1965 shows that after removal of acetylphosphokinase there remains a carbamoyl phosphokinase which, in regard to mutation and regulation, behaves like the glutamine-dependent reaction described by Piérard \& Wiame (1964). This would mean that in $E$. coli the biosynthetic enzyme is not absolutely specific for glutamine but is able to use $\mathbf{N H}_{4}{ }^{+}$with a lower affinity. This favours the idea that glutamine is the true physiological substrate. The $\boldsymbol{E}$. coli system thus appears as intermediate between Saccharomyces cerevisiae and the Neurospora systems, so far as the nitrogen donor is concerned. That one enzyme, according to its source, can utilize $\mathrm{NH}_{4}{ }^{+}$or glutamine or both, as nitrogen donor for an amidation or amination reaction is not unusual. Meister (1962) and Levenberg (1962) pointed out several cases of such dual sources of nitrogen, particularly in the synthesis of purine and pyrimidine nucleotides.

Carbamoyl phosphate is a common donor of the carbamoyl group for the synthesis 
of arginine and pyrimidines, thus constituting a branching point in metabolic pathways. This raises difficulties for understanding the regulation of these biosyntheses, a problem solved in similar cases (reviewed by Stadtman, 1963; Wiame, 1965) by the existence of independent enzymes responsible for the synthesis of the common product. The existence of two enzymes permits the independent regulation of two syntheses and as a further refinement may lead to different structural associations of these enzymes in relation to their respective functions. Different kinds of evidence may suggest the existence of two different enzymes when two functions have to be

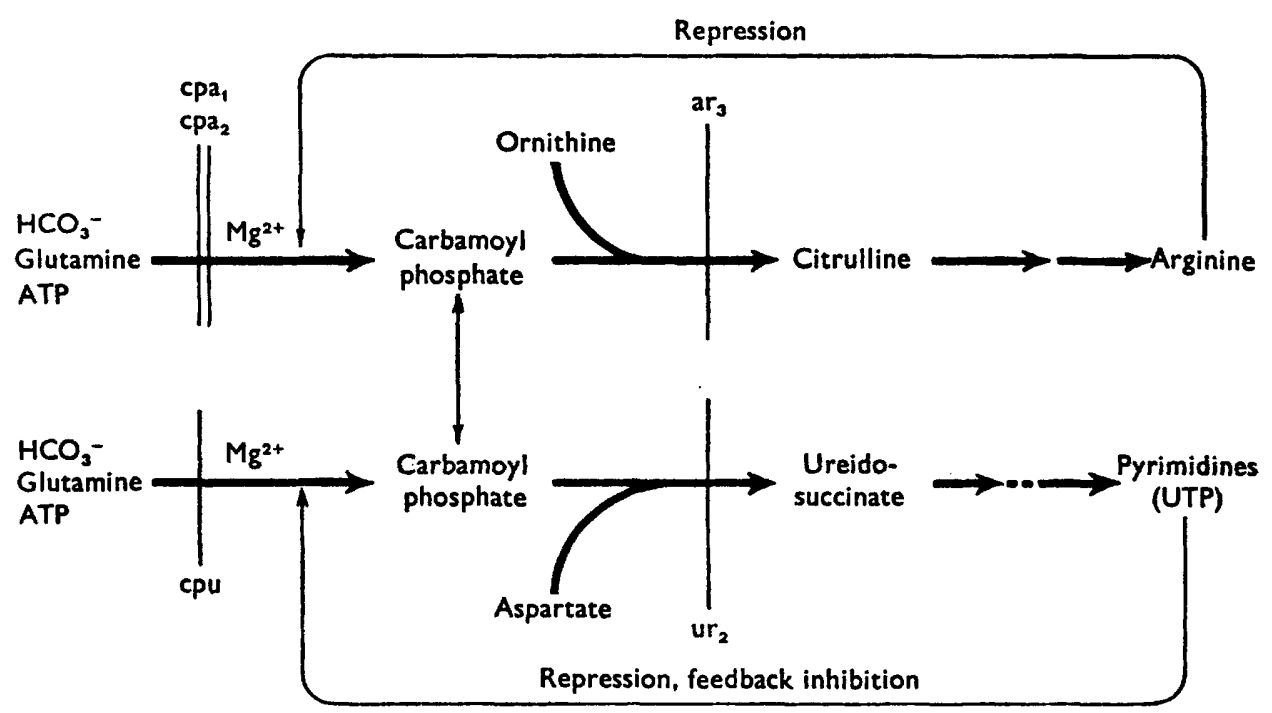

Fig. 6

fulfilled. The most conclusive proof is the demonstration of two physically separable enzymes, each affected by a specific mutation and regulated in accordance with their function. In the case of Saccharomyces cerevisiae, the data presented in this paper and summarized in Fig. 6 permit the conclusion that there exist two enzymes responsible for the synthesis of carbamoyl phosphate. They have not been physically separated but both can be affected by specific mutations $(c p a, c p u)$ and in this way they can be studied separately with respect to their regulation. Both are much more active with glutamine than with $\mathrm{NH}_{4}{ }^{+}$. The enzyme present in the strain $\left(c p u, c p a^{+}\right)$is strongly repressed by arginine. The enzyme of strain $\left(c p a, c p u^{+}\right)$is markedly retro-inhibited by uridine- 5 -triphosphate. The strains which carry both mutations $c p u$ and cpa have no activity, and are auxotrophic for arginine and pyrimidines. The properties of the enzymes leave no doubt about their function: one is related to the biosynthesis of arginine, the other to the biosynthesis of pyrimidines. However, carbamoyl phosphate formed by either enzyme is available in vivo for both syntheses and the two types of mutants are able to grow on a minimal medium. There is no indication of a channelling, despite genes cpu and $u r_{2}$ (for aspartate carbamoyltransferase) being allelic, as in Neurospora (Woodward \& Davis, 1963). The enzymes corresponding to both these genes are sensitive to feed-back inhibition by UTP (Lacroute, 1964).

In Escherichia coli, since one mutation leads to double auxotrophy for arginine 
and uracil, it has to be admitted that there is a common catalytic element for the carbamoyl phosphate synthesis by both pathways. This raises a problem since it seems that both arginine and uracil have cumulative effect in the repression of this activity (Piérard \& Wiame, 1964).

In Neurospora (Dr R. H. Davis, personal communication), it was anticipated since 1960 that there would be two different enzymes for carbamoyl phosphate synthesis, one for arginine, the other for pyrimidines. The basis for such an idea came from the study of Neurospora mutants arg-3 and pyr-3a. These mutants are, respectively, auxotrophic for arginine and a pyrimidine. Nutritional studies locate their deficiencies in the synthesis of carbamoyl phosphate, leading to the hypothesis that not only are there two independent systems for carbamoyl phosphate synthesis but also that the carbamoyl phosphate which arises from each system is channelled to its related function. Experiments to be published have shown that carbamoyl phosphate can be shunted to the other function by a mutation which affects its normal route of utilization. A question left open in Neurospora is the nature of the reaction which supplies carbamoyl phosphate for the pyrimidine pathway. The significance of mutant arg-2, not allelic but phenotypically identical with arg-3, remains to be elucidated. While mutant arg-3 exhibits a complete loss of carbamoyl phosphokinase activity, arg-2 retains this activity. Two non-allelic genes $\left(c p a_{1}, c p a_{2}\right)$ determine the arginine specific carbamoyl phosphate biosynthetic system of Saccharomyces cerevisiae. However, in contrast to Neurospora mutants arg-2 and arg-3, both $S$. cerevisiae mutations $c p a_{1}$ and $c p a_{2}$ lead to a deficiency in the arginine-specific carbamoyl phosphate synthesis. Several hypotheses may be put forward to explain these facts. A first explanation would be that one gene is the structural gene, the other being a regulator gene. However, this hypothesis must be discarded since the combination of the cell-free extracts of single mutants carrying these two mutations regain activity. Two alternatives are left: (i) existence of two enzymic steps, each gene determining one enzyme; (ii) a single enzyme made up of two kinds of subunits, each kind corresponding to one of the genes. Preliminary experiments do not allow a distinction between the two possibilities.

We are grateful to Dr G. Kaplan for help in the preparation of the manuscript. We thank Drs L. Gorini, J. Yashphe and R. H. Davis for making their papers available to us before publication. We also thank Mr R. Kutzner and Miss F. Muyldermans for excellent technical assistance. This work was supported in part by grants of the Rockefeller Foundation and of the Commissariat à l'Energie Atomique to the Laboratoire de Génétique Physiologique du C.N.R.S., in part by subsidies of the Institut pour l'Encouragement de la Recherche Scientifique dans l'Industrie et l'Agriculture and of the Fonds de la Recherche Scientifique Fondamentale Collective to the Laboratoire de Microbiologie, Université de Bruxelles and to the Institut de Recherches du C.E.R.I.A.

\section{REFERENCES}

Beckwith, J. R., Pardee, A. B., Austrian, R. \& Jacob, F. (1962). Coordination of thə synthesis of the enzymes in the pyrimidine pathway of $E$. coli. J. molec. Biol. 5,618 .

Bishop, S. H. \& CAMpBell, J. W. (1963). Carbamyl phosphate synthesis in the earthworm Lumbricus terrestris. Science, $142,1583$.

Charles, H. P. (1962). Response of Neurospora mutants to carbon dioxide. Nature, Lond. 195, 359. 
Cohen, P. P. (1962). In The Enzymes, Ed. by P. D. Boyer, H. Lardy \& K. Myrbäch. Vol. 6, p. 477. New York: Academic Press Inc.

Davis, B. D. (1962). Cited in The Bacteria, Ed. by I. C. Gunsalus \& R. Y. Stanier. New York and London: Academic Press.

Davis, R. H. (1962). Consequences of a suppressor gene effective with pyrimidine and proline mutants of Neurospora. Genetics, 47, 351.

DAvis, R. H. (1963). Neurospora mutant lacking an arginine specific carbamyl phosphokinase. Science, 142, 1652.

Davis, R. H. \& Woodward, V. W. (1962). The relationship between gene suppression and aspartate transcarbamylase activity in pyr-3 mutants of Neurospora. Genetics, 47, 1075.

Gorini, L. \& Kalman, S. M. (1963). Control by uracil of carbamyl phosphate synthesis in Escherichia coli. Biochim. biophys. Acta, 69, 355.

Grisolia, S. \& Harmon, P. (1962). Acetyl phosphate utilization with animal and bacterial enzymes. Biochim. biophys. Acta, 7, 357.

Grisolia, S., Ameiunxen, R. \& Raijman, L. (1963). Acetyl and carbamyl phosphate utilization with aspartate transcarbamylase and carbamate kinase. Biochem. Biophys. Res. Communs. 11, 75.

Hawthorne, D. C. \& Mortimer, R. K. (1960). Chromosome mapping in Saccharomyces: centromere-linked genes. Genetics, 45, 1085.

Jones, M. E. (1963). Carbamyl phosphate. Science, 140, 1373.

Jones, M. E., Spector, L. \& Lipmann, F. (1955). Carbamyl phosphate, the carbamyl donor in enzymatic citrulline synthesis. $J$. Am. chem. Soc. 77, 819.

LAcroute, F. (1964). Un cas de double rétro-contrôle: la chaîne de biosynthèse de uracile chez la levure. C.r. Séanc. Soc. Biol. 259, 1357.

Lacroute, F., Piérard, A., Grenson, M. and Wiame, J. M. (1964). La biosynthèse du carbamyl phosphate chez Saccharomyces cerevisiae. Arch. int. Physiol. Biochim. $72,687$.

Levenberg, B. (1962). Role of L-glutamine as donor of carbamyl nitrogen for the enzymatic synthesis of citrulline in Agaricus bisporus. J. biol. Chem. 237, 2590.

Meister, A. (1962). In The Enzymes, Ed. by P. D. Boyer, H. Lardy \& K. Myrbäch. Vol. 6, p. 247. New York and London: Academic Press.

Miller, E. J. \& Harrison, J. S. (1950). Growth inhibition of yeast by uracil, and its reversal by arginine. Nature, Lond. 166, 1035.

Novick, R. P. \& MaAs, W. K. (1961). Control by endogenously synthesized arginine of the formation of ornithine transcarbamylase in Escherichia coli. $J$. Bact. 81, 236.

Ochod, S. \& Stern, J. R. (1952). Carbohydrate metabolism. Ann. Rev. Biochem., 21, 547.

Pićrard, A., \& Wrame, J. M. (1964). Regulation and mutation affecting a glutamine dependent formation of carbamyl phosphate in Escherichia coli. Biochem. Biophys. Res. Communs. 15, 76.

Reissig, J. L. (1960). Forward and back mutation in the pyr-3 region of Neurospora. I. Mutation from arginine dependence to prototrophy. Genet. Res. 1, 356.

REISsig, J. L. (1963). Spectrum of forward mutants in the pyr-3 region of Neurospora. J. gen. Microbiol. 30, 327.

Roepke, R. R. (1946) cited in Tatum, F. L. Induced Biochemical Mutations in Bacteria. Cold Spring Harb. symp. Quant. Biol. 11, p. 278.

Sомцо, M. (1962). La L-lacticodéshydrogénase de la levure aérobie. Comparaison des propriétés de l'enzyme lié et de l'enzyme soluble. Biochim. biophys. Acta. 65, 333.

Stadtman, E. R. (1963). Symposium on multiple forms of enzymes and control mechanism. II. Enzyme multiplicity and function in the regulation of divergent metabolic pathways. Bact. Rev. 27, 170.

Thorne, K. J. I. \& Jones, M. E. (1963). Carbamyl and acetyl phosphokinase activities of Streptococcus faecalis and Escherichia coli. J. biol. Chem. 238, 2992.

Wiame, J. M. (1965). La régulation d'embranchements métaboliques. Colloques Cent. natn. Rech. scient. Marseille; Juillet 1963

Woodward, V. W. \& Davis, R. H. (1963). Coordinate changes in complementation, suppression and enzyme phenotypes of a pyr-3 mutant of Neurospora crassa. Heredity, $18,21$.

YASHPHe, J. \& GoRINi L. (1965) Phosphorylation of carbamate in vivo and in vitro. J. biol chem. 240, 1681. 